The amplifying and buffering effects of virtuousness in downsized organizations

By: David S. Bright, Kim S. Cameron, and Arran Caza

Bright, D., Cameron, K.S., \& Caza, A. (2006). The amplifying and buffering effects of virtuousness in downsized organizations. Journal of Business Ethics, 64 (3), 249-269. https://doi.org/10.1007/s10551-005-5904-4

This is a post-peer-review, pre-copyedit version of an article published in Journal of Business Ethics. The final authenticated version is available online at: http://dx.doi.org/10.1007/s10551-005-5904-4.

****(C) 2006 Springer. Reprinted with permission. No further reproduction is authorized without written permission from Springer. This version of the document is not the version of record and is subject to Springer Nature terms of reuse for archived author accepted manuscripts. ***

\begin{abstract}
:
Virtuousness refers to the pursuit of the highest aspirations in the human condition. It is characterized by human impact, moral goodness, and unconditional societal betterment. Several writers have recently argued that corporations, in addition to being concerned with ethics, should also emphasize an ethos of virtuousness in corporate action. Virtuousness emphasizes actions that go beyond the "do no harm" assumption embedded in most ethical codes of conduct. Instead, it emphasizes the highest and best of the human condition. This research empirically examines the buffering and amplifying effects of virtuousness in organizations. The study hypothesizes that virtuousness has a positive effect on organizations because amplifying dynamics make subsequent virtuous action more likely, and buffering dynamics reduce the harmful effects of downsizing. The study reveals that two types of virtuousness - tonic and phasic - are associated with these effects.
\end{abstract}

Keywords: ethics | virtuousness | virtues | downsizing

\title{
Article:
}

Recent scandals have prompted a growing interest in corporate ethics and social responsibility (Dawkins and Lewis, 2003). Concomitant with this interest, increased attention has also been paid to the issue of virtues and virtuousness in organizations (Cameron et al., 2003). An organizational ethos of virtuousness refers to the pursuit of the highest aspirations in the human condition (MacIntyre, 1984). It is argued to be a useful orientation providing proactive guidance in times of difficulty (Arjoon, 2000; Caza et al., 2004). Virtuousness is suggested to not only help organizations avoid wrongdoing, but to enhance the likelihood that they will pursue higher levels of individual and societal benefit as well (Arjoon, 2000; Bolino et al., 2002).

Virtuousness differs from ethics in that choices are made, not only from the standpoint of living within the constraints of ethical rules, but also from the perspective of building personal and 
communal excellence (Arjoon, 2000; Dobson, 2004). Thus, virtuousness is a different kind of standard that guides individuals to enact excellence in character and moral judgment (Cameron, 2003; Caza et al., 2004). This study identifies indicators of two types of virtuousness, tonic and phasic, and their relationships to effectiveness in downsized organizations.

The benefit of research on virtuousness as a complement to ethics derives from two basic premises. First, ethical codes cannot predict every possible dilemma managers will face in the turbulent external environment (Arjoon, 2000; Caza et al., 2004). Most corporate codes of conduct function as a regulatory force to prevent serious lapses in ethical judgment. Yet, no system of rules can anticipate or give guidance regarding moral correctness in every situation. This is particularly true when change is ubiquitous, making it difficult to find right answers based on conflicting moral arguments. For example, many of the perpetrators in the scandals at Enron made their decisions based on a frame-of-reference that seemed perfectly legitimate and ethical to company insiders. Indeed, many of them still claim that they did nothing wrong (Cohan, 2002). In such situations, an ethos of virtuousness can act as a beacon that transcends situational dynamics. It enables behaviors and decisions that rise above what is merely expected in ethical conduct.

Second, the absence of unethical behavior does not guarantee the presence of highly principled behavior. Ethical standards define a minimum threshold for performance and decision-making. However, actions that extend beyond this minimal standard cannot be understood if the behaviors and actions beyond the threshold remain unexplored. The differences between unethical, ethical, and virtuousness-driven behaviors, for example, can be described in terms of a continuum of deviance from normal or acceptable behavior in Figure 1 (Cameron, 2003). The left end of the continuum refers to negative deviance, which can be characterized by harmful, unethical, or dishonest behavior. The middle point represents acceptable, normal, or ethical behavior. The right end of the continuum describes positive deviance characterized by virtuousness or flourishing. By definition, all organizations exist to facilitate a normal, nondeviant condition (Weick et al., 1999). When deviance exists - either positive or negative organizational mechanisms are mobilized to pressure a return to a consistent, predictable, and reliable state. The middle point on the continuum is the ordinary, normal, expected, comfortable condition (Spreitzer and Sonenshein, 2003).

\begin{tabular}{cllr|} 
& Negative Deviance & Normal & Positive Deviance \\
\cline { 3 - 4 } Phenomenon & Illness & Health & Wellness \\
Ehysiology & Ineffective & Effective & Excellence \\
Relationships & Harmful & Helpful & Honoring \\
Ethics & Unethical & Ethical & Virtuousness
\end{tabular}

Figure 1. Continuum illustrating differences in the characteristics of social science phenomena. Adapted from Cameron (2003, p. 53). 
To focus on the left side of the continuum is to emphasize recovery, healing, and problem solving. It is consistent with a "do no harm" or "repair the damage" (ethics) perspective. To focus on the right side of the continuum is to emphasize abundance, positivity, and vitality. It is consistent with a "do good" or "enable the best" (virtuousness) perspective. This continuum illustrates that a focus on left side, ethical issues is important for organizational success, but it focuses primarily on the prevention of wrong rather than promotion of good. On the other hand, right side issues encourage virtuous thinking because of a concern with the development of excellence in human and organizational character (Peterson and Seligman, 2004).

The dynamics associated with movement toward the right end of the continuum are seldom explored in empirical studies of ethics (Dyck and Kleyson, 2001). However, some evidence indicates that the social dynamics associated with positive deviance are distinct from those associated with negative deviance (Cameron et al., 2003). For instance, Fredrickson (2003) has demonstrated that positive emotions emerging from dynamics on the right side of the continuum are associated with an expansion in cognitive thought-processes - people broaden the information to which they pay attention and use more of their cognitive abilities when experiencing positive emotions. Negative emotions, on the other hand, are more frequently associated with the left side of the continuum. They are associated with a narrowing in cognitive focus and behavior patterns in individuals (Fredrickson and Losada, 2005).

This study explores dynamics on the right side of the continuum in Figure 1 - that is, virtuousness in organizations. It empirically examines the presence of virtuousness and its effects on organizational performance. The study pays special attention to the relationship between organizational virtuousness and the effects of downsizing. First, we provide an overview of virtuousness and describe specifically how it is manifest in organizations. Next, we explain two hypotheses relating to how an ethos of virtuousness produces both amplifying and buffering effects. Third, we describe a data gathering effort and an analysis of data that examine two hypotheses. Finally, we discuss implications of this research.

\section{Defining virtuousness}

Virtuousness has roots in the Latin word virtus, meaning "strength" or "excellence." Anciently, Plato and Aristotle described virtues as the desires and actions that produce personal and social good. More recently, virtuousness has been described as the best of the human condition, the most ennobling of behaviors and outcomes, the excellence and essence of humankind, and the highest aspirations of human beings (Cameron, 2003; Comte-Sponville, 2001; MacIntyre, 1984; Tjeltveit, 2003). An ethos of virtuousness refers to the pursuit of this condition.

"Virtuousness" refers to the ideal state of excellence in human or organizational character, while "virtues" are the specific manifestations of a particular type of character excellence. In an ethos of virtuousness, "the foundation of morality lies in the development of good character traits as virtues," for which both individuals and organizations have responsibility (Arjoon, 2000; Nesteruk, 1996). Indeed, in the original Greek, virtuousness (arête) was recognized as being demonstrated at both the individual and the collective level (Schudt, 2000). Research on community virtuousness defines it as an embedded characteristic of culture, whereby "being virtuous" means adopting and adhering to the highest qualities of the social system of which one 
is a part (Jordan and Meara, 1990; Hillelfarb, 1996). Virtuousness, in this sense, is the internalization of moral rules that produces social harmony (Baumeister and Exline, 1999).

However, organizational virtuousness entails more than the socialization of members. Virtuous organizations contribute to the ethical development of their members (Morse, 1999), and they have "strengths that make it possible for individuals to flourish as human beings and to pursue uniquely human aims and goods" (Fowers and Tjeltveit, 2003).

\section{Characteristics of virtuousness}

Three key definitional attributes are associated with organizational virtuousness, namely human impact, moral goodness, and unconditional societal betterment (Cameron, 2003). First, virtuousness is associated with human beings - with flourishing and moral character (Ryff and Singer, 1998), with human strength, self-control, and resilience (Baumeister and Exline, 1999), and with meaningful life purpose and transcendent principles (Emmons, 1999). Desires or actions without positive human impact are not virtuous.

Second, virtuousness is associated with moral goodness; it represents what is good and worthy of cultivation (McCullough and Snyder, 2000). Much debate has occurred regarding what constitutes "goodness," yet all societies and cultures possess catalogs of traits that they deem virtuous and praiseworthy (Park and Peterson, 2003). In this sense, virtuousness guides all ethical codes or principles, which can be interpreted as an attempt to operationalize what is right or just (Morse, 1999). What is commonly construed as "the good" is defined within the boundaries of organizing communities, and "the common good is achieved when each person contributes to the whole in accord with his or her abilities and with the awareness of the legitimate needs of others." (Arjoon, 2000, p. 165). The existence of universal conceptions of moral goodness is supported by recent work reported in the field of Positive Psychology, culminating in a volume on virtues and strengths that integrates ideas from many world cultures, histories, and spiritual traditions (Peterson and Seligman, 2004).

Third, virtuousness is characterized by unconditional social betterment that extends beyond mere self-interested benefit and creates social value which transcends the instrumental desires of the actor. This unconditionality also differentiates virtuousness from traditional ethics, citizenship behavior, and corporate social responsibility insofar as these activities are often motivated by instrumental benefit or exchange relationships. For instance, Aristotle (2003, p. 611) differentiated between goods of first intent, or that "which is, in itself, worthy of pursuit.... always desirable in itself and not for something else" (e.g. love, wisdom, and fulfillment) and goods of second intent or "that which is good for the sake of obtaining something else" (e.g. profit, prestige or power). People are satiated by goods of first intent, whereas the rewards from goods of second intent may be fleeting (Cameron, 2003).

Virtuousness fosters actions that are based on a motivation of human excellence that transcends instrumental reciprocity (Peterson and Seligman, 2004) without intent to induce a specific response in or from others. Decisions are made based on the perspective that a choice is "the right thing to do," even in the absence of clearly definable benefits. When behavior is designed to acquire benefit for the firm or to create a reciprocal arrangement - for example, acquiring a 
positive corporate reputation in exchange for socially responsible activities - it cannot be defined as virtuousness (Weiser and Zadek, 2000). Moreover, associating virtuousness with purely instrumental motives can change the intrinsic nature of activity into "another technique of manipulation and discipline" (Gergen, 1990, p. 154), thereby destroying the inherent virtuousness of the action in the first place. This idea is consistent with the Aristotelian notion of eudemonia, "which holds that well-being is not a consequence of virtuous action, but rather an inherent aspect of such action" (Park and Peterson, 2003).

Organizational virtuousness

As noted above, virtuousness has been conceived as both an individual and collective state. At the collective level, organizational virtuousness can take two forms: virtue in organizations and virtue through organizations. Virtuousness in organizations relates to the behavior of individuals in organizational settings that helps people flourish as human beings (Fowers and Tjeltveit, 2003). The manifestation and consequences of individual virtues such as hope, gratitude, wisdom, forgiveness, courage, and other similar virtues have received increasing attention in the psychological literature (Emmons and Crumpler, 2000; McCullough et al., 2000; Seligman, 2002a, b; Snyder, 2000; Sternberg, 1998). Virtuousness through organizations relates to the enablers in organizations that foster and perpetuate virtuousness. When it occurs in organizations, groups of people act in ways that demonstrate virtuousness, which may include actions that would not be possible for individuals to achieve by acting alone. Moreover, the effect of collective virtuousness may support a condition where the impulse to seek human excellence becomes a part of the organization's culture (Cameron et al., 2004; Gunther, 2004).

Although organizational virtuousness is not motivated by instrumental outcomes, there is reason to expect that virtuousness produces, as a byproduct, many positive organizational outcomes. Evidence for the effects of two virtues, compassion and forgiveness, are illustrative.

Forgiveness is associated with broader and richer social relationships, higher satisfaction, greater feelings of empowerment, less physical illness, faster recovery from disease and injury, and less depression and anxiety in people than those holding unforgiving feelings and attitudes (Fitzgibbons, 1986; McCullough, 2000; Witvliet, 2001). Compassionate persons demonstrate higher levels of helping behavior, moral reasoning, connectedness, and stronger interpersonal relationships, as well as less depression, reduced moodiness, and less mental illness than those not demonstrating compassion (Cassell, 2002; Solomon, 1998). In fact, associations between individual virtuousness and performance have received an increasing amount of support in positive psychology literature (e.g. Clifton and Harter, 2003; Emmons, 2003). Likewise, studies at an organization level have demonstrated a link between virtuous business practices and a general improvement in performance (Cameron et al., 2004; Margolis and Walsh, 2003). The key to these benefits is that they ensue from the pursuit of virtuousness, not as an end in themselves, but rather as a side effect (Baker, 2001).

\section{Indicators of virtuousness}

Our approach to the operationalization of virtuousness was informed by Peterson and Seligman's (2004) effort to synthesize universal conceptions of virtues and human strengths. Their work 
thematically captured common virtues across most cultures and nationalities, and it documented the language used to describe several categories of virtues which fulfill the three criteria of human impact, moral goodness, and unconditional social betterment. In our investigation, we selected several indicators of virtuousness which have research support at the individual level and which can be explored in organizations. Park and Peterson (2003) also suggest that virtues can be described as one of two types: either tonic or phasic. Tonic virtuousness is a generalized condition, whereas phasic virtuousness is dependent on an external event. Tonic virtuousness can exist anytime (e.g., integrity can be constantly present), whereas phasic virtuousness occurs only when an event creates a need for it (e.g., a personal offense initiates the need for forgiveness). Consistent with their perspective, we use these terms to differentiate between a propensity to demonstrate virtuousness compared to actual virtuous actions.

\section{Tonic Virtuousness}

In organizations, tonic virtuousness is ambient in that it represents normative assumptions about what "should be done," influences espoused values, and promotes specific behaviors (Hackman, 1992; Schein, 1992). In virtuous organizations, members are enabled to express virtues; they are hopeful, humble, just, kind, etc. In the current study hope, humility-modesty, integrity, kindness, and virtuous purpose are used as indicators of tonic organizational virtuousness.

Hope is the capacity to see, expect, believe, or emotionally anticipate the best for an expected future (Snyder et al., 2002) and is associated with numerous individual and social benefits (Peterson, 1991; Snyder et al., 2002). Optimistic individuals have better social relationships in organizational settings, as well as higher levels of physical health, academic and athletic performance, recovery from illness and trauma, pain tolerance, self-efficacy, and flexibility in thinking (Peterson, 1991; Snyder et al., 2002). Hope-optimism is a learned virtue (Seligman, 1991) that varies with social circumstances. When fostered in organizational settings it produces especially positive social outcomes, such as goal achievement, empowerment, and agency (Snyder et al., 2000).

Humility-Modesty, known as a "quiet" virtue (Tangney, 2002), is often misunderstood to be selfdepreciation or low self-esteem (Klein, 1992). A humble or modest person is not selfaggrandizing but is capable of maintaining a tempered perspective of him or herself (Richards, 1992). Humility involves a sense of self-acceptance that includes an understanding of strengths and accomplishments as well as weaknesses and limitations (Clark, 1992); hence, it is best described as openness to learning. It is an "increase in the valuation of others, not a decrease in the valuation of oneself" (Means et al., 1990). Humility in leadership also has ties with economic success in organizations (Collins, 2001).

Integrity is manifest through maintaining consistent standards, trustworthiness, and displays of honesty (Harter, 2002). Integrity requires thought, timing, tact, and empathy in expressing what one holds as truth (Lerner, 1993). When individuals display integrity they maintain congruency among thoughts, feelings, and actions (Rogers, 1951). Integrity facilitates productive interpersonal relationships, successful teamwork, effective decision making, high levels of participation, and a positive organizational climate (Lerner, 1993). 
Kindness is a defining human characteristic (Kanov et al., 2004) involving empathetic concern for others (Solomon, 1998). For German phenomenologists, it was considered one of the foundations of ethical living (Peterson and Seligman, 2004). Kindness through compassion is often manifested in organizations when pain, suffering, or distress is experienced, but it also can describe a generalized condition. Kindness in organizations facilitates a sense of humanity, assists healing, and nurtures interpersonal connections (Dutton et al., 2002; Frost et al., 2000). Restoring or enabling a sense of kindness, belonging, and life-giving relationships among people at work is a direct result of acts of compassion in organizations (Frost, 1999).

Virtuous purpose refers to the broad quest for excellence or virtuousness. It is associated with a sense of meaningfulness in an organization (Pratt and Ashforth, 2003; Wrzesniewski, 2003). It is a condition in which individuals define their work as being personally meaningful, of significance, or in harmony with what they care about deeply. When virtuous purpose or a sense of calling has been fostered in organizations, workers experience higher levels of job and life satisfaction, stronger commitment to the organization, less conflict, more trust in management, healthier team process, more satisfaction with coworkers, and higher involvement in the work itself than in normal organizations (Wrzesniewski et al., 1997).

\section{Phasic Virtuousness}

Another form of virtuousness occurs only when certain conditions arise, such as a shock or punctuated event. Phasic virtuousness is manifest through specific virtuous behaviors that occur in response to the event. For example, the September 11 disaster gave rise to various forms of virtuousness such as courage and compassion. In the present study, downsizing is seen as producing similar conditions - violations of trust, personal harm, organizational deterioration (e.g., Cameron, 1998; Cascio et al., 1997) - which provide opportunities for expressions of virtuousness throughout the organization. Two phasic virtues were measured: forgiveness and responsibility. For example, organization members may demonstrate forgiveness of leaders for having taken the difficult decision to downsize. Similarly, organizational leaders may take responsibility for the damage caused to displaced workers and to the organization as a result of their decision to downsize.

Forgiveness is a specific action that occurs when people dissolve negative feelings, psychic pain, or desire for revenge that follow harmful or offensive actions (Bright, 2005; Bright et al., in press; McCullough and Worthington, 1994; McCullough et al., 2000). The offended person chooses to abandon resentment, negative judgment, bitterness, and indifferent behavior and may experience an increase in positive emotions, affirmative motivations, and prosocial behavior toward the offender (McCullough and Witvliet, 2002; McCullough et al., 2000). Forgiveness has psychic, emotional, and behavioral dimensions and has been linked to several mental, physiological, and social benefits (see McCullough and Witvliet, 2002 for a review). Forgiveness also occurs at the collective level when groups or organizations reframe an offense such that they shed the victim's role and instead adopt a prosocial response to the violation or damage (Yamhure Thompson and Shahen, 2003). When people forgive they are not condoning harm or wrong-doing, nor do they give up the right to social justice. Rather, forgiveness is coping with the psychological costs of others' actions and making a mindful decision not to harbor deepseated anger or thoughts of revenge. 
Taking responsibility is also a phasic virtue in which individuals acknowledge awareness of and accountability for the difficulty or harm caused to others through actions and decisions taken. Responsibility focuses on acting in the best interest of the common good rather than selfpreservation (Peterson and Seligman, 2004). In one form, taking responsibility can be expressed through remorse or an apology where awareness of the linkage between one's actions and the consequences of those actions is demonstrated. Taking responsibility is not necessarily an acknowledgement that one has acted wrongfully or incorrectly, but rather that one "owns" the full range of consequences that are related to a particular decision or action. It is linked to some theories of social justice (Rawls, 1971), and psychologists suggest that it is also closely linked to empathy (Eisenberg, 1986). People who take responsibility generally feel a sense of identity with others (Brewer and Gardner, 1996; Dawes et al., 1990). Forgiveness is more likely when offenders take responsibility for their actions (Girard and Mullet, 1997; McCullough et al., 1997, 1998).

\section{Downsizing as a context for studying virtuousness}

We chose organizations that had recently downsized as sites for our study of virtuousness because of the well-established deleterious effects of downsizing (Cameron, 1998; Cascio et al., 1997). In most downsized organizations, morale, trust, and productivity suffer; a majority of organizations fail to achieve the desired results of their downsizing initiatives; and fewer than $10 \%$ of firms report an improvement in quality, innovation, or organizational climate. Among companies with similar growth rates, those that do not downsize consistently outperform those that do, and restructured firms tend to decline in returns on investment after downsizing and do not recover enough to match non-downsizing firms three years later (Cameron, 1994, 1998).

These negative outcomes in performance are associated with a variety of internal problems created by downsizing. They include (1) the destruction of interpersonal relationships, shared values, trust and loyalty, and commonality in culture and values; (2) reduced information sharing and increased secrecy, deception, and duplicity; (3) increased formalization, rigidity, resistance to change, and conservatism; (4) increased conflict, anger, vindictiveness, and feelings of victimization; and (5) increased selfishness and voluntary turnover, as well as deterioration in teamwork and cooperation. Typically, downsizing leads to perceptions of injustice, life disruption, and personal harm (Cameron et al., 1987; McKinley et al., 1995). Non-virtuous responses typically include blaming, holding grudges, seeking retribution, and displaying selfinterest (Staw et al., 1981).

Yet, in spite of these consistent, long-term negative patterns in most firms that downsize, exceptions do exist. Some organizations flourish and improve after downsizing. They overcome the deleterious responses to layoffs, job losses, and contract violations (Cameron, 1994). We hypothesize that virtuousness is helpful in explaining the existence of these exceptional cases. Specifically, two key attributes of virtuousness may help explain its potential relationship with the long-term deleterious effects of downsizing: its buffering qualities, which protect the organization against negative consequences (Sutcliffe and Vogus, 2003), and its amplifying qualities, which foster escalating positive consequences (Fredrickson and Joiner, 2002). 
Virtuousness buffers the organization from the negative effects of downsizing by enhancing resiliency, commitment, and a sense of efficacy (Dutton et al., 2002; Masten and Reed, 2002; Weick et al., 1999). Fostering virtuousness during prosperous times deepens and enhances resiliency, or the ability to absorb threat and trauma and to bounce back from adversity (Dienstbier and Zillig, 2002; Fredrickson et al., 2000), by enhancing the preservation of social capital and collective efficacy (Sutcliffe and Vogus, 2003). These buffering effects suggest the following hypothesis:
Hypothesis 1: Both phasic and tonic virtuousness buffer the organization from deteriorating performance such that:
la.Tonic virtuousness is negatively related to the long-term deleterious effects of downsizing,
1b. Forgiveness (phasic virtue) is negatively related to the long-term deleterious effects of downsizing, and
1c. Responsibility (phasic virtue) is negatively related to the long-term deleterious effects of downsizing.

In addition to the buffering effect of virtuousness in organizations that downsize, tonic and phasic virtuousness also may produce an amplifying effect (Cameron, 2003; Cameron et al., 2004). The amplifying effect of virtuousness can occur in at least two ways. First, Fredrickson (1998) and Seligman (2002a) reported that virtuous behaviors produce positive emotions, leading to a replication of virtuousness and an elevation in positive well-being (Fredrickson, 2003). In turn, positive emotions build high-quality relationships among organization members (Bolino et al., 2002; Dutton and Heaphy, 2003). Second, virtuousness fosters prosocial behavior. When people are guided by images of "goodness" and act from an intrinsic motivation to help (Krebs, 1987), others feel compelled to join with and build upon their contributions (e.g. Sethi and Nicholson, 2001). Observing and experiencing virtuousness unlocks predispositions to act for the benefit of others, causing an upward spiral, and increasing social connections in an organization (Feldman and Khademian, 2003).

In essence, virtuous actions lead to and inspire more virtuous actions. When they become commonplace, the organization itself is characterized by generalized (tonic) virtuousness. Moreover, when tonic virtuousness epitomizes an organization, it is more likely that phasic virtuousness will be displayed as well.

For instance, McCullough and Witvliet (2002) demonstrated that responsibility expressed through an apology is linked to forgiveness. Remorseful displays provide people with more perspective about the degree of harmful intention in a particular decision (e.g. downsizing for the survival of the company, a more virtuous pursuit because it preserves the common good, versus downsizing merely to increase profitability), an instrumental pursuit. Apologetic leaders are seen empathetically as more human, which has the effect of reducing motivations toward vengeance. Hence, expressions of responsibility amplify the willingness of organizational members to forgive the harm caused by downsizing decisions.

Furthermore, forgiveness has been shown to be associated with positive outcomes like greater trust, humanness, compassion, and caring in relationships (McCullough and Snyder, 2000). 
Under conditions of downsizing, the presence of both tonic and phasic virtuousness should enable organization members to nurture a climate that supports a collective abandonment of grudges, bitterness, and blame. In addition, expressions of responsibility and forgiveness should enhance a climate of tonic virtuousness in organizations as well. The hypothesis following from these relationships can be stated as follows:

\section{Hypothesis 2: Demonstrations of virtuousness amplify additional demonstrations of virtuousness such that: \\ 2a: Responsibility (phasic virtuousness) is positively related to forgiveness (phasic virtuousness), \\ 2b: Forgiveness (phasic virtuousness) is positively related to tonic virtuousness; 2c: Responsibility (phasic virtuousness) is positively related to tonic virtuousness.}

\section{Method}

Instrument development

A primary concern of this study was to develop measures that assess the presence of organization-level virtuousness, so a multi-step process was followed. Field interviews led to survey item-generation, which was followed by survey data collection. Exploratory Factor Analysis and Confirmatory Factor Analysis were conducted to test the initial survey items and to construct a final measurement structure.

\section{Field interviews}

Two recently downsized organizations were selected for an interview study based on their reputations in the popular press as especially virtuous organizations. One organization is a relatively small regional hospital in the Northeast United States ( 800 employees, sample $\mathrm{N}=25$ ), and the second organization is a multi-national environmental and engineering consulting firm (10,000 employee, sample $\mathrm{N}=50)$ with headquarters in the Western United States. Both organizations have been listed in the "Fortune Magazine's Best 100 Companies to Work For," are privately owned, and have recently won national awards for excellence in various aspects of their businesses. In addition, both experienced financial turnaround after a downsizing, and employees attributed part of the turnaround to the institutionalization of virtuousness as a core part of their businesses. Our objective was not to independently confirm the veracity of these perceptions but rather to understand the elements that indicated the presence of virtuousness.

Semi-structured interviews were conducted with a cross-section of employees at each organization with questions designed to understand how virtuousness was manifest in the organizations, how virtuousness was facilitated or inhibited, and how virtuousness might be assessed. Approximately 25 people participated in the interviews at the hospital, and approximately 50 individuals at three different locations participated at the engineering and environmental firm. Employees represented a diagonal slice of their organizations, meaning across hierarchical levels and across functions. 
Those interviews, coupled with a review of the literature, led to the development of a several questionnaire items designed to assess organizational virtuousness, including tonic virtues (i.e., hope-optimism, humility, integrity, compassion, virtuous fulfillment) and phasic virtues (i.e., responsibility and forgiveness). All items employed a six-point scale, where 6 represented strong agreement and 1 represented strong disagreement. To measure the long-term deleterious effects of downsizing, we used the Dirty Dozen scale (Cameron et al., 1987), a measure of the negative long-term impacts of downsizing.

\section{Sample}

Fifty-two organizations representing a convenience sample were invited to participate in the study by means of a personal contact with the CEO or company president. No prior knowledge about organizational virtuousness guided the sample selection. Eighteen organizations agreed to participate (36\%), representing 16 different industries from retail, manufacturing, steel, automotive, public relations, transportation, business consulting, healthcare, power generation, and social services. The data were collected during 2001. All but two organizations had downsized within the prior 5 years.

At the individual respondent level, a total of 1437 surveys were distributed, and 820 questionnaires (56\%) were received. Of these, 647 (45\%) provided data regarding the effects of downsizing in their organizations. In each of the 18 participating firms, a company liaison distributed the surveys to a randomly selected diagonal sample of employees (i.e., across levels and functions). All individuals and their organizations were guaranteed anonymity. The total number of downsized respondents per company ranged from 11 to 96 . To check within-sample characteristics, we computed sub-sample mean scores for the hierarchical level of respondents in the organization and for tenure with the organization, which revealed under-representation of lower hierarchical levels in some companies. Accordingly, we controlled for these sample artifacts in the subsequent analysis.

\section{Exploratory factor analysis}

Principal axis factoring (PAF) with a Promax (oblique) rotation indicated that a two-factor solution differentiating tonic virtues from phasic virtues was the most appropriate way to model this data (Eigenvalue $_{\text {tonic virtue }}=23.035$, Eigenvalue $_{\text {phasic virtue }}=2.538,58 \%$ variance explained). The pattern matrix from this analysis, along with the items for downsizing, are listed in Appendix A.

\section{Confirmatory factor analysis}

Using Analysis of MOment Structures (AMOS), we performed CFA to establish the convergent and discriminant validity of the data and to test for common method variance. The final model included nine downsizing items and six tonic virtuousness items, and we retained a split in the phasic virtues between four forgiveness items, and a single responsibility item (see Appendix A). Indices of fit were well within generally acceptable parameters $\left(\chi^{2}[147]=420.4, p<0.001\right.$, $\mathrm{RMSEA}=0.059, \mathrm{SRMR}=0.044, \mathrm{CFI}=0.959, \mathrm{NFI}=0.939, \mathrm{PCFI}=0.824, \mathrm{PNFI}=0.807)$. 
Based upon these results, we computed single composite factors from the means of the items for Downsizing, Tonic Virtuousness, and the two phasic virtues of Forgiveness and Responsibility. Means, standard deviations, and correlations are found in Table I. All correlations are in the expected direction and commensurate with those derived in the CFA.

TABLE I. Descriptive statistics and correlations

\begin{tabular}{|lccccc|}
\hline & Mean & Std. & $\mathbf{1}$ & $\mathbf{2}$ & $\mathbf{3}$ \\
\hline 1. Tonic Virtuousness & 4.13 & 1.03 & & & \\
2. Forgiveness & 3.65 & 1.18 & 0.51 & & \\
3. Responsibility & 3.77 & 1.52 & 0.38 & 0.57 & \\
4. Downsizing & 3.31 & 1.10 & 0.56 & 0.66 & 0.43 \\
\hline
\end{tabular}

All correlations are significant at $\mathrm{p}<0.001$.

$N=627$.

Aggregation issues

All constructs shown in Table I were conceptualized at the individual level to capture general perceptions of organization characteristics. To justify this level of aggregation and to assess the potential violation of independence, given that subjects rated their own organizations, we calculated scores of interrater agreement/consensus $\left(r_{\mathrm{wg}(\mathrm{j})}\right)$ on a uniform expected variance distribution (James et al., 1984). We also calculated two intraclass correlations - ICC(1) and ICC(2) - and an F-test for the ICC(1) (Bliese, 2000). Average interrater agreement was slightly below the 0.70 benchmark proposed by James et al. (1984) for Downsizing $\left(r_{\mathrm{wg}(\mathrm{j})}=0.60\right)$, Tonic Virtuousness, $\left(r_{\mathrm{wg}(\mathrm{j})}=0.68\right)$, Forgiveness $\left(r_{\mathrm{wg}(\mathrm{j})}=0.66\right)$, and unacceptably below the benchmark for Responsibility $\left(r_{\mathrm{wg}(\mathrm{j})}=0.24\right)$. The $\mathrm{ICC}(1)$ and $\mathrm{ICC}(2)$ values were 0.08 and 0.72 for Downsizing $(F(d f)=3.544(17),<0.001), 0.12$ and 0.82 for Tonic Virtuousness $(F(d f)=5.530(17), p<0.001)$, 0.13 and 0.79 for Forgiveness $(F(d f)=4.743(17), p<0.001)$, and 0.09 and 0.49 for Responsibility $(F(d f)=1.978(17), p=0.011)$.

These scores suggested organization-level systematic differences. We determined to use mixedlevel regression models to separate between- and within-organization effects. As an aid in interpretation, we created both organization- and individual-level scores for each of the independent factors (Singer, 1998). At the organization level, we centered the scores for Tonic Virtuousness, Forgiveness, and Responsibility about their grand means, then aggregated to generate group mean scores. At the individual level we calculated standardized group centered scores (z-scores from the group mean). To improve the interpretability for the control factors of hierarchical level and tenure, we adjusted the mean-hierarchical level and mean tenure scores to a baseline of zero.

Analysis

We used the SAS MIXED program to generate all results. Three sets of effects provide tests for the hypotheses: Forgiveness regressed on Responsibility (Model 1); Tonic Virtuousness regressed on Forgiveness and Responsibility (Model 2); and Downsizing regressed on Forgiveness, Responsibility, and Tonic Virtuousness (Model 3). We calculated an unconditional means (ANOVA) model, organization-level effects, and individual-level effects for each model (Singer, 1998). 
TABLE II. Results of mixed regression analyses

\begin{tabular}{|c|c|c|c|c|c|c|c|c|c|c|c|c|}
\hline \multirow[b]{3}{*}{ Parameter } & \multicolumn{4}{|c|}{$\begin{array}{c}\text { Forgiveness } \\
\end{array}$} & \multicolumn{4}{|c|}{ Tonic Virtuousness } & \multicolumn{4}{|c|}{ Downsizing } \\
\hline & \multicolumn{2}{|c|}{ ANOVA } & \multicolumn{2}{|c|}{ Model 1} & \multicolumn{2}{|c|}{ ANOVA } & \multicolumn{2}{|c|}{ Model 2} & \multicolumn{2}{|c|}{ ANOVA } & \multicolumn{2}{|c|}{ Model 3} \\
\hline & b & s.e. & b & s.e. & b & s.e. & $\begin{array}{ll}b \\
\end{array}$ & s.e. & b & s.e. & b & s.e. \\
\hline \multicolumn{13}{|l|}{ Fixed effects } \\
\hline$\gamma_{00}$, Intercept (mean of intercepts) & $3.76^{* * *}$ & 0.11 & $5.04^{* * *}$ & 0.52 & $4.23^{* * *}$ & 0.01 & $3.91^{* * *}$ & 0.55 & $3.23^{* * *}$ & 0.09 & $3.16^{* * *}$ & 0.35 \\
\hline \multicolumn{13}{|l|}{ Organization-level $(N=18)$} \\
\hline$\gamma_{01}$, Mean tenure of org respondents & & & $-0.38^{*}$ & 0.15 & & & 0.18 & 0.15 & & & -0.02 & 0.11 \\
\hline$\gamma_{02}$, Mean level of org respondents & & & -0.22 & 0.18 & & & -0.05 & 0.16 & & & 0.06 & 0.10 \\
\hline$\gamma_{03}$, Tonic Virtuousness (within-group mean) & & & & & & & & & & & -0.28 & 0.19 \\
\hline$\gamma_{04}$, Forgiveness (within-group mean) & & & & & & & $0.55^{\dagger}$ & 0.27 & & & $-0.52^{*}$ & 0.20 \\
\hline$\gamma_{05}$, Responsibility (within-group mean) & & & 0.52 & 0.38 & & & $0.76^{\dagger}$ & 0.35 & & & -0.02 & 0.04 \\
\hline \multicolumn{13}{|l|}{ Individual-level $(N=627)$} \\
\hline$\gamma_{30}$, Tonic Virtuousness (within-group z) & & & & & & & & & & & $-0.27^{* * *}$ & 0.04 \\
\hline$\gamma_{40}$, Forgiveness (within-group z) & & & & & & & $0.43^{* * *}$ & 0.04 & & & $-0.54^{* * *}$ & 0.04 \\
\hline$\gamma_{50}$, Responsibility (within-group z) & & & $0.67^{* * *}$ & 0.04 & & & $0.1^{*}$ & 0.04 & & & -0.02 & 0.04 \\
\hline \multicolumn{13}{|l|}{ Residual effects } \\
\hline$\sigma^{2}$, Variance in level-1 residual & $1.28^{* * *}$ & 0.07 & $0.83^{* * *}$ & 0.05 & $1.03^{* * *}$ & 0.06 & $0.78^{* * *}$ & 0.05 & $1.12^{* * *}$ & 0.06 & $0.60^{* * *}$ & 0.03 \\
\hline$\sigma_{00}$, Variance in intercepts & $0.19^{* *}$ & & $0.11^{*}$ & 0.05 & $0.14^{* *}$ & 0.06 & $0.08^{*}$ & 0.04 & $0.10^{*}$ & 0.05 & $0.02^{\dagger}$ & 0.02 \\
\hline Total level-1 variance explained & & & 0.45 & & & & 0.25 & & & & 0.52 & \\
\hline$\%$ of Level-1 variance explained & & & $35 \%$ & & & & $24 \%$ & & & & $46 \%$ & \\
\hline
\end{tabular}

$\dagger p<0.10,{ }^{*} p<0.05,{ }^{* *} p<0.01,{ }^{* * *} p<0.001$. 


\section{Results}

The mixed regression results are reported in Table II. The mean scores, as shown by the ANOVA intercepts for the dependent factors Forgiveness, Tonic Virtuousness, and Downsizing were $3.76,4.23,3.23$, respectively, before controlling for any other factor. The level-1 residuals $\left(\sigma^{2}\right)$ show significant variance due to differences in individual responses, and variance across intercepts $\left(T_{00}\right)$ indicates marginally significant differences in means across the 18 organizations. This indicates that the survey instrument captured differences among respondents and among their organizations.

The results for the test of Hypothesis 1 are found in Model 3 in Table II. All other factors being 0 , the mean score for Downsizing is 3.23, and none of the organization-level effects are highly significant. The individual-level measures for Tonic Virtuousness $(b=-0.27 ; p<0.001)$ and Forgiveness $(b=-0.54 ; p<0.001)$ are strong and significant, indicating support for an inverse effect on the deleterious effects of downsizing from both tonic and phasic forms of virtuousness. Responsibility did not exhibit a direct relationship to Downsizing. The model explains $46 \%$ of the individual-level variance, and lends general support to Hypothesis 1. That is, tonic virtuousness clearly buffers the deleterious effects of downsizing (H1a).

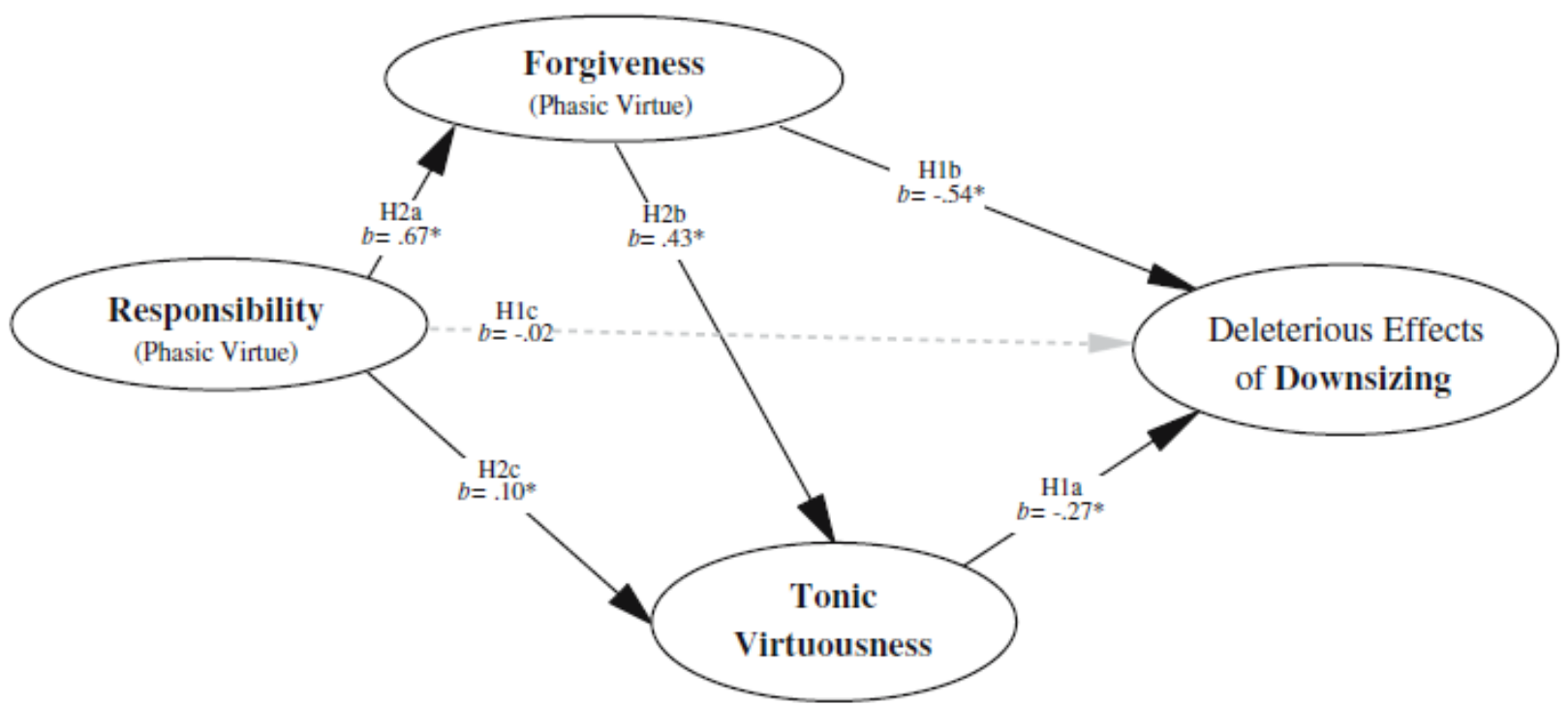

Figure 2. Summary of regression relationships between Phasic Virtuousness, Tonic Virtuousness and the deleterious effects of downsizing. Effects significant at $p<0.01$ or greater (H1c is the only non-significant effect).

The tests for Hypothesis 2 are illustrated in Models 1 and 2 in Table II. All other factors being 0, the means for Forgiveness and Tonic Virtuousness are 3.76 and 4.23, respectively. Model 1 shows that the mean tenure has a moderately significant, negative relationship with Forgiveness $(b=-0.38 ; p=0.02)$. As predicted, the within-group individual relationship of Responsibility to Forgiveness is highly significant and positive $(b=0.67, p<0.001)$. The overall effect of Model 1 explains $35 \%$ of the individual-level variance in Forgiveness. In Model 2, both organization and individual-level scores for Responsibility $\left(b_{\text {org }}=0.76, p=0.06 ; b_{\text {ind }}=0.10, \mathrm{p}=0.01\right)$ and Forgiveness $\left(b_{\text {org }}=0.55, p=0.06 ; b_{\text {ind }}=0.43, p<0.001\right)$ are significantly related to Tonic 
Virtuousness. The overall effect of Model 2 explains $24 \%$ of the individual-level variance in Tonic Virtuousness. Considered together, Models 1 and 2 support the second hypothesis. That is, the presence of phasic virtuousness tends to foster tonic virtuousness and vice versa. A summary of the regressions relationships generated by these findings is illustrated in Figure 2.

\section{Discussion}

Amplifying and buffering effects

In this study, we found mixed support for the buffering effects of virtuousness in organizations (Hypothesis 1). To reiterate, buffering is manifest as a capacity to absorb systems shocks, bounce back, heal relationships, and collaborate. It provides a form of resilience in organizations (Sutcliffe and Vogus, 2003). Where organizations received high evaluations of virtuousness, they were also more proficient at carrying on in spite of the setbacks associated with downsizing. The data showed that both Forgiveness (H1a) and Tonic Virtuousness (H1b) have an inverse relationship with the deleterious impact of downsizing, providing evidence for a substantive buffering effect. Forgiveness showed the strongest relationship; however, Responsibility (H1c) showed no direct relationship. Thus, the evidence suggests that organizations tend to be more resilient when they are characterized by both tonic and phasic virtuousness, but especially specific forms of phasic virtuousness.

We also found strong support for the amplifying effect of virtuousness (Hypothesis 2). In the amplifying effect, virtuousness in organizations becomes generalized to virtuousness through organizations. That is, a single display of virtuous action in organizations has the potential to create systems and practices that make virtuousness through organizations more likely. In this study, Responsibility was associated with more Forgiveness (H2a), and both Forgiveness (H2b) and Responsibility (H2c) were associated with more Tonic Virtuousness. The amplifying effect also accounts for the fact that we did not find support for a direct buffering effect of Responsibility on the deleterious effects of downsizing (H1c). That is, employees were more inclined to express forgiveness when top managers expressed some form of responsibility. Indeed, it appears that forgiveness almost completely mediates the buffering effect of responsibility. Because virtuous actions tend to inspire other virtuous actions, this means that the overall effect of virtuousness on the recovery of an organization from downsizing may in fact depend on the degree to which the amplifying effect takes hold. This finding suggests the importance of linked, cyclical demonstrations of virtuousness in organizations.

Research implications

Four phenomena are related to research on the amplifying and buffering effects of virtuousness and the self-reinforcing nature of tonic and phasic virtues revealed in this study (Cameron, 2003; Cameron et al., 2004): the generation of positive emotions, the formation of social capital, the demonstration of prosocial behavior, and the relative impact of different forms of virtuousness. 
First, Fredrickson (1998), Seligman (2002a, 2002b), Fineman (1996) and other scholars have found that virtuous behaviors produce positive emotions in individuals, which, in turn, lead to a replication of virtuousness and an elevation in positive well-being. For instance, when organization members observe compassion, experience love, or witness forgiveness, they increase their pride in the organization, enjoyment of the work, satisfaction with the job, and thereby experience "love, empathy, verve, zest, and enthusiasm . . . the sine qua non of managerial success and organizational excellence" (Fineman, 1996, p. 545). Studies have demonstrated that this sense of affective elevation - which is fostered by observing virtuousness - is disseminated throughout an organization by way of a contagion effect (Barsade, 2002).

However, as demonstrated in this article, the relationship between virtuousness and emotions extends to negative experiences as well, such as downsizing. Relationships within organizations do not always promote positive emotions. It is an endemic characteristic of human interaction that people will take offense at one another. Virtues like forgiveness are directly related to how people choose to manage these negative experiences. Bright (2005) found that forgiveness can harness negative emotions to create experiences that lead to positive emotions. In the process, positive emotions "undo" the deleterious effects of negative emotions (Fredrickson, 2000). The implications of this link between virtuousness and the emergence and management of emotions in organizations can be examined in future research.

\section{Social capital}

A second reason for the amplifying effects of virtuousness is its association with the formation of social capital. A key characteristic of social capital is the degree to which people experience high quality connections with one another (Dutton and Heaphy, 2003). Social capital in organizations is important because it reduces transaction costs, facilitates communication and cooperation, enhances employee commitment, fosters individual learning, strengthens relationships and involvement, and, ultimately, enhances organizational performance (Adler and Kwon, 2002). Organizations function better when members know, trust, and feel positively toward one another (Bolino et al., 2002). Observing virtuous actions creates a sense of attachment and attraction towards virtuous actors (Bolino et al., 2002) which, in turn, helps members of an organization experience a compelling urge to join with and build upon the contributions of these actors (Eisenberg, 1986; Sethi and Nicholson, 2001). In other words, the amplifying effect of observing virtuousness creates a self-reinforcing tendency toward more virtuousness, and this potentially leads to stronger relationships that build the social capital in organizations. These potential relationships between virtuousness and social capital deserve further scrutiny.

\section{Prosocial behavior}

Virtuousness also fosters prosocial behavior. Prosocial behavior occurs when individuals behave in ways that benefit other people. Usually it is explained as being motivated by an exchange relationship, reciprocity, or equity (McNeeley and Meglino, 1994) in which individuals attempt to reciprocate to those who benefit them. In the case of virtuousness, however, several authors (e.g., Batson, 1991, 1994) have pointed out that individuals engage in prosocial behavior because of internal definitions of goodness and an intrinsic motivation toward helping others. "Evidence on impulse helping suggests that ...individuals may be genetically disposed to engage in 
impulsive acts of helping" (Krebs, 1987, p. 113). Observing and experiencing virtuousness helps unlock the human predisposition toward behaving in ways that benefit others. Studies reported by Cialdini (2000) and Asche (1952) support the idea that when people observe exemplary or moral behavior, their inclination is to follow suit. Hence, positive spirals of prosocial behavior, following from spirals of positive affect, tend to flow from virtuous behavior. In sum, research on virtuousness provides a basis for examining additional motives for prosocial behavior other than self-interest.

\section{Relative impacts of virtuousness}

The failure to find support for Hypothesis 1c is intriguing. The demonstrated buffering effects of forgiveness and tonic virtue indicate an indirect effect of responsibility on organizational performance; that is, responsibility contributed to forgiveness and tonic virtue, and both of those affect downsizing results. This finding raises the question of which virtues have direct effects and which have solely indirect ones. For example, why no direct effect for responsibility? For one thing, the deleterious effects of downsizing are associated with harbored negativity. Taking responsibility can be viewed as a form of apology, as acknowledging that one has harmed others. It does not involve the actual transformation of negativity, whereas this transformation is integral to the process of forgiveness. Thus, taking responsibility only has an effect to the extent that it facilitates forgiveness; accepting responsibility may be a first step, but its effect is only realized to the extent that it fosters more forgiveness.

The idea that there are direct and indirect effects may also extend to the level of analysis of demonstrated virtuousness within organizations. For instance, the impact of a single person who demonstrates virtuousness (virtuousness in organizations) may be mediated by the extent to which it is scaled up through an amplifying effect within an organization (virtuousness through organizations). Indeed, the most substantive benefits of virtuousness may come about only when demonstrations of virtuousness become widespread within an organization.

Implications for management

These findings also have several implications for practical issues. First, these results indicate the importance for managers to talk about and support virtuous action in organizations. Given that a few virtuous deeds have the potential to create organization wide effects, leaders should be trying to foster virtuousness. According to Peterson and Seligman (2004), virtuousness is manifest through demonstrations of courage (e.g. integrity and persistence), humanity (e.g. kindness and compassion), justice (e.g. responsibility and fairness), temperance (e.g. forgiveness and humility), and transcendence (e.g. hope and optimism). To the extent that managers live by and encourage the practice of such virtues as a regular modus operandi, they foster a reserve of resiliency and strength within organizations that can be drawn on as a significant resource during difficult periods.

Second, managers are perhaps must vulnerable and in need of employee support when they undertake the most challenging of decisions. For instance, in this study, the decision to downsize can be seen as a decision that both hurts employees yet also asks surviving employees to contribute at a higher level. Where employees see that managers and organizations do not take 
seriously a concern for workers - that is, where an organization is NOT seen as virtuous employees are less likely to respond favorably when confronted with challenging trying organizational circumstances. In contrast, when employees see that an organization and its leaders consistently strive to treat workers with fairness, integrity, compassion, etc - when an organization is seen as more virtuous - employees are more likely to work with, rather than against managers in organizations. This fact should encourage managers to consistently seek for and practice forms of virtuousness. Doing so will encourage a dynamic that will mitigate the potentially deleterious effects of downsizing or other similarly difficult decisions.

In this regard, it is uncommon to hear talk of virtuousness in organizations (Cameron and Caza, 2003), and most organizational leaders do not overtly discuss or demonstrate virtuousness (Walsh, 1999). Clearly, there is need for research about why hints of virtuousness tend to be suppressed in most organizations, what facilitates or prohibits virtuous acts in organizations, and what can be done to promote them.

Finally, these results have substantial implications for the downsizing literature. Most research on downsizing has focused on the negative impacts of downsizing, and how to downsize in a way that mitigates these negative impacts. This article is unique because it has focused on the "positive outliers" (Spreitzer and Sonenshein, 2003), or those organizations that do not follow the typical trend. In essence, the findings in this article provide an explanation for why a minority of downsized firms flourish, in spite of the negativity induced by downsizing. The results suggest a way for managers to determine the outcome of a decision to downsize. For instance, they might take stock of the degree of perceived virtuousness within their organizations. If the perception of virtuousness is low, then it is likely that the decision to downsize will actually contribute to a continued toxic atmosphere and to a weakened financial position. Such information could cause managers to think twice about looking to downsizing as an easy path to renewed profitability. Instead, managers may be encouraged to focus attention on the dynamics of virtuousness that may allow for people to connect with others at a higher level, which could bring about desired improvements in organizational performance.

\section{Conclusions}

This paper has empirically examined the role of virtuousness as an extension to ethics in organizations. Virtuousness is expressed both in and through organizations because of its amplifying and buffering effects. The amplifying effect is shown as the tendency to repeat and reinforce similar virtuous actions when forgiveness is expressed, when public responsibility is demonstrated for a harmful decision, and when compassion is expressed in response to pain or suffering. Employees who observed evidence of virtuousness in their organizations clearly viewed their organizations as less affected by the usual long-term, negative effects of downsizing. The buffering effect is seen in the ability of organizations to be resilient during traumatic, challenging moments, such as those associated with downsizing. When leaders in organizations consistently strive to display tonic and phasic virtuousness in their behavior, these actions generate a substantial amount of goodwill which, in turn, increases a reserve of buffering capacity. The negative effects of decisions such as downsizing are minimized or mitigated altogether. Organization leaders and members can have impact on the extent to which 
virtuousness characterizes their organization's culture by perpetuating these amplifying and buffering effects.

Overall, the findings demonstrate the importance of discussing not only ethics but also virtuousness in organizational actions. The findings also illustrate why an understanding of virtuousness - characterized by a focus on abundance, positivity, and pursuing the good - is essential to exceptional organizing. Indeed, an ethos of virtuousness can be a "liberating, inspirational force" (Arjoon, 2000, p. 162) during trial and trauma in organizational life. Virtuous acts serve as a beacon during uncertain times or in situations that call for thinking beyond the "do no harm" assumption embedded in most ethical codes of conduct.

In sum, in light of the current environment in which deteriorating confidence in business and attributions of corruption and negative deviance are widespread, organizational studies will benefit from an expanded exploration of virtuousness - the highest of human potential, ennobling qualities, and transcendent purposes. Such efforts have the potential to provide more guidance and a higher standard to organizations that falter when relying solely on ethical decision-making.

\section{Acknowledgements}

The support of the John Templeton Foundation (grant \#5110) is gratefully acknowledged. We also express appreciation to Loren Dyck, Ryan Falcone, Richmond Teo and Erica Friedman for assistance in data collection. We are grateful to the organizations that willingly provided data for this study. Thanks are also due to the editor and two anonymous reviewers for their comments. Related data from this study are reported in Cameron, K., Bright, D.S., and Caza, A. 2003. American Behavioral Scientist, 47 (6): 766-790.

\section{References}

Adler, P. S. and S. Kwon: 2002, 'Social Capital: Prospects for a New Concept', Academy of Management Review 27, 17-40.

Aristotle: 2003, 'Nicomachean Ethics', in S. M. Cahn (ed.), Philosophy for the 21st Century (Oxford, New York), pp. 610-618.

Arjoon, S.: 2000, 'Virtue Theory As a Dynamic Theory of Business', Journal of Business Ethics 28(2), 159-178.

Asche, S. E.: 1952, Social Psychology (Prentice Hall, Englewood Cliffs, NJ).

Baker, W.: 2001, Achieving Success Through Social Capital: Tapping Hidden Resources in Your Personal and Business Networks (Jossey-Bass, San Francisco).

Barsade, S. G.: 2002, 'The Ripple Effect: Emotional Contagion and its Influence on Goup Behavior', Administrative Science Quarterly 47(4), 644-675.

Batson, C. D.: 1991, The Altruism Question: Toward a Social-Psychological Answer (Lawrence Erlbaum, Hillsdale NJ). 
Batson, C. D.: 1994, 'Why Act for the Public Good? Four Answers', Personality and Social Psychology Bulletin. 20, 603-610.

Baumeister, R. F. and J. Exline: 1999, 'Virtue, Personality, and Social Relations: Self-Control As Moral Muscle', Journal of Personality 67, 1165-1194.

Bliese, P. D.: 2000, 'Within-Group Agreement, Non-Independence, and Reliability: Implications for Data Aggregation and Analysis', in K. J. Klein and S. W. J. Kozlowski (eds.), Multilevel Theory, Research, and Methods in Organizations (Jossey-Bass, San Francisco), pp. 349-381.

Bolino, M. C., W. H. Turnley and J. M. Bloodgood: 2002, 'Citizenship Behavior and the Creation of Social Captial in Organizations', Academy of Management Review 27(4), 505-522.

Bright, David S.: 2005, 'Forgiveness and Change: Begrudging, Pragmatic, and Transcendent Responses to Discomfiture in a Unionized Trucking Company' Unpublished Dissertation, Case Western Reserve University, Cleveland, OH (Dissertation Abstractions International).

Bright, D. S., R. E. Fry and D. L. Cooperrider: In press, 'Forgiveness from the Perspectives of Three Response Modes: Begrudgement, Pragmatism, and Transcendence', Journal of Management Spirituality and Religion.

Brewer, M. B. and W. Gardner: 1996, "Who is This "We"? Levels of Collective Identity and Self Representations', Journal of Personality and Social Psychology 71, 83-93.

Cameron, K. S.: 1994, 'Strategies for Successful Organizational Downsizing', Human Resource Management Journal 33, 189-211.

Cameron, K. S.: 1998, 'Strategic Organizational Downsizing: An Extreme Case', Research in Organizational Behavior 20, 185-229.

Cameron, K. S.: 2003, 'Organizational Virtuousness and Performance', in K. S. Cameron, J. E. Dutton and R. E. Quinn (eds.), Positive Organizational Scholarship (Barrett-Koehler, San Francisco), pp. 48-65.

Cameron, K. S., D. S. Bright and A. Caza: 2004, 'Exploring the Relationships between Organizational Virtuousness and Performance', American Behavioral Scientist 47(6), 766-790.

Cameron K. S. J. E. Dutton R. E. Quinn.: 2003, Positive Organizational Scholarship (BarrettKoehler, San Francisco).

Cameron, K. S., M. U. Kim and D. A. Whetten: 1987, 'Organizational Effects of Decline and Turbulence', Administrative Science Quarterly 32, 222-240.

Cascio, W. F., C. Young and J. R. Morris: 1997, 'Financial Consequences of Employment Change Decisions in Major US Corporations', Academy of Management Journal 40, 1175-1189. 
Cassell, E. J.: 2002, 'Compassion', in C. R. Snyder and S. J. Lopez (eds.), Handbook of Positive Psychology (Oxford University Press, New York), pp. 434-443.

Caza, A., B. Barker and K. Cameron: 2004, 'Ethics and Ethos: The Amplifying and Buffering Effects of Ethical Behavior and Virtuousness', Journal of Business Ethics 52, 169-178.

Cialdini, R. B.: 2000, Influence: The Science of Persuasion (Allyn Bacon, New York).

Clark, A. T.: 1992, 'Humility', in D. H. Ludlow (eds.), Encyclopedia of Mormonism (Macmillan, New York), pp. 663-664.

Clifton, D. O. and J. K. Harter: 2003, 'Investing in Strengths', in K. S. Cameron, J. E. Dutton and R. E. Quinn (eds.), Positive Organizational Scholarship: Foundations of a New Discipline (Berrett Koehler, San Francisco), pp. 111-121.

Cohan, J. A.: 2002, “I Didn’t Know' and 'I Was Only Doing My Job': Has Corporate Governance Careened Out of Control?’ Journal of Business Ethics 40(3), 275-300.

Collins, J.: 2001, Good to Great: Why Some Companies Make the Leap... and Others Don't (Harper-Collins, New York).

Comte-Sponville: 2001, (Trans. C. Temerson), A Small Treatise of the Great Virtues (Metropolitan Books, New York).

Dawes, R. M., A. J. C. van de Kragt and J. Orbell: 1990, 'Cooperation for the Benefit of Us: Not Me, or My Conscience', in J. J. Mansbridge (eds.), Beyond Self-Interest (University of Chicago Press, Chicago), pp. 97-110.

Dawkins, J. and S. Lewis: 2003, 'CSR in Stakeholder Expectations: And their Implications for Company Strategy', Journal of Business Ethics 44(2/3), 185-193.

Dienstbier, R. A. and L. M. Zillig: 2002, 'Toughness', in C. R. Snyder and S. J. Lopez (eds.), Handbook of Positive Psychology (Oxford University Press, New York), pp. 515-527.

Dobson, J.: 2004, 'Applying Virtue Ethics in Business: The Agent-Based Approach', Electronic Journal of Business Ethics and Organization Studies, 9(1). World-wide web access at http://ejbo.jyu.fi.

Dutton, J. E., P. J. Frost, M. C. Worline, J. M. Lilius and J. M. Kanov: 2002, 'Leading in Times of Trauma', Harvard Business Review, 80(1), 54-61.

Dutton, J. E. and E. D. Heaphy: 2003, 'The Power of High-Quality Connections’, in K. S. Cameron, J. E. Dutton and R. E. Quinn (eds.), Positive Organizational Scholarship: Foundations of a New Discipline (Berrett Koehler, San Francisco), pp. 263-278.

Dyck, B. and R. Kleysen: 2001, 'Aristotles Virtues and Management Thought: An Empirical Exploration of an Integrative Pedagogy’, Business Ethics Quarterly 11(4), 561.

Eisenberg, N.: 1986, Altruistic Emotion, Cognition, and Behavior (Erlbaum, Hillsdale, NJ).

Emmons, R. A.: 1999, The Psychology of Ultimate Concerns: Motivation and Spirituality in Personality (Guildford Press, New York). 
Emmons, R. A.: 2003, 'Acts of Gratitude in Organizations', in K. S. Cameron, J. E. Dutton and R. E. Quinn (eds.), Positive Organizational Scholarship: Foundations of a New Discipline (Berrett Koehler, San Francisco), pp. 81-93.

Emmons, R. A. and C. A. Crumpler: 2000, 'Gratitude As a Human Strength: Appraising the Evidence', Journal of Social \& Clinical Psychology 19(1), 56-69.

Feldman, M. S. and A. M. Khademian: 2003, 'Empowerment and Cascading Vitality', in K. S. Cameron, J. E. Dutton and R. E. Quinn (eds.), Positive Organizational Scholarship: Foundations of a New Discipline (Berrett Koehler, San Francisco), pp. 343-358.

Fineman, S.: 1996, 'Emotion and Organizing', in S.R. Clegg, C. Hardy and W. R. Nord (eds.), The Handbook of Organizational Studies (Sage, London), pp. 543-564.

Fitzgibbons, R. P.: 1986, 'The Cognitive and Emotive Uses of Forgiveness in the Treatment of Anger', Psychotherapy 23(4), 629-633.

Fowers, B. J. and A. C. Tjeltveit: 2003, 'Virtue Obscured and Retrieved: Character, Community, and Practices in Behavioral Science', American Behavioral Scientist 47(4), 387-394.

Fredrickson, B. L.: 1998, 'What Good Are Positive Emotions?', Review of General Psychology 2, 300-319.

Fredrickson, B. L.: 2003, 'Positive Emotions and Upward Spirals in Organizations', in K. S. Cameron, J. E. Dutton and R. E. Quinn (eds.), Positive Organizational Scholarship: Foundations of a New Discipline (Berrett Koehler, San Francisco), pp. 163-175.

Fredrickson, B. L. and T. Joiner: 2002, 'Positive Emotions Trigger Upward Spirals Toward Emotional Well-Being', Psychological Science 13(2), 172.

Fredrickson, B. L., R. A. Mancuso, C. Branigan and M. M. Tugade: 2000, 'The Undoing Effect of Positive Emotions', Motivation \& Emotion 24(4), 237-258.

Fredrickson, B. L. and Losada, M.: 2005, 'Positive Affect and the Complex Dynamics of Human Flourishing', American Psychologist, 60(7), 678-686.

Frost, P.: 1999, 'Why Compassion Counts!', Journal of Management Inquiry 8(2), 127-133.

Frost, P. J., J. E. Dutton, M. C. Worline and A. Wilson: 2000, 'Narratives of Compassion in Organizations', in S. Fineman (ed.), Emotion in Organizations (Sage Publications, Thousand Oaks, CA), p. 25-45.

George, J. M.: 1995, 'Leader Positive Mood and Group Performance: The Case of Customer Service', Journal of Applied Social Psychology 25(9), 778-794.

Gergen, K. J.: 1990, 'Affect and Organization in Postmodern Society', in S. Srivastva and D. L. Cooperrider (eds.), Appreciative Management and Leadership: The Power of Positive Thought and Action in Organizations. (Jossey-Bass Inc., San Francisco), pp. 153-174.

Girard, M. and E. Mullet: 1997, 'Propensity to Forgive in Adolescents, Young Adults, Older Adults, and Elderly People', Journal of Adult Development 4, 209-220. 
Gunther, M.: 2004, Faith and Fortune: The Quiet Revolution to Reform America's Business (Crown Business, New York).

Hackman, J. R.: 1992, 'Group Influences on Individuals in Organizations', in M. D. Dunnett and L. M. Hough (eds.), Handbook of Industrial and Organizational Psychology (Consulting Psychologists Press, Palo Alto, CA), pp. 199-267.

Harter, S.: 2002, 'Authenticity', in C. R. Snyder and S. J. Lopez (eds.), Handbook of Positive Psychology (Oxford University Press, New York), pp. 382-394.

Hillelfarb, G.: 1996, The De-Moralization of Society: From Victorian Virtues to Modern Values (Vintage, New York).

James, L. R., R. J. Demaree and G. Wolf: 1984, 'Estimating Within-Group Interrater Reliability With and Without Response Bias', Journal of Applied Psychology 69, 85-98.

Jordan, A. E. and N. M. Meara: 1990, 'Ethics and the Professional Practice of Psychologists: The Role of Virtues and Principles', Professional Psychology Research and Practice 21, 107114.

Kanov, J. M., S. Maitlis, M. C. Worline, J. E. Dutton, P. J. Frost and J. M. Lilius: 2004, 'Compassion in Organizational Life', American Behavioral Scientist 47(6), 808-827.

Klein, D. C.: 1992, 'Managing Humiliation', Journal of Primary Prevention 12, 255-268.

Krebs, D.: 1987, 'The Challenge of Altruism in Biology and Psychology', in C. Crawford, M. Smith and D. Krebs (eds.), Sociobiology and Psychology (Lawrence Erlbaum, Hillsdale, NJ).

Lerner, H. G.: 1993, The Dance of Deception (Harper Collins, New York).

MacIntyre, A.: 1984, 'The Nature of the Virtues', in A. MacIntyre (eds.), After Virtue: A Study in Moral Theory 2nd edition, (Notre Dame Press, Notre Dame, IN).

Margolis, J. D. and J. P. Walsh: 2003, 'Misery Loves Companies: Rethinking Social Initiatives by Business', Administrative Science Quarterly 48(2), 268-305.

Masten, A. S. and G. J. Reed: 2002, 'Resilience in Development', in C. R. Snyder and S. J. Lopez (eds.), Handbook of Positive Psychology (Oxford University Press, New York), pp. $74-88$.

McCullough, M. E., K. C. Rachal, S. J. Sandage, E. L. Worthington, Jr., S. W. Brown and T. L. Hight: 1998, 'Interpersonal Forgiving in Close Relationships: II. Theoretical Elaboration and Measurement', Journal of Personality and Social Psychology 75, 1586-1603.

McCullough, M.E.: 2000, 'Forgiveness As Human Strength: Theory, Measurement, and Links to Well-Being', Journal of Social and Clinical Psychology 19(1),43-55.

McCullough M. E. K. I. Pargament C. E. Thoresen.: 2000, Forgiveness: Theory, Research, and Practice (The Guilford Press, New York).. 
McCullough, M. E. and C. R. Snyder: 2000, 'Classical Source of Human Strength: Revisiting an Old Home and Building a New One', Journal of Social and Clinical Psychology 19(1), 110.

McCullough, M. E. and C. V. Witvliet: 2002, 'The Psychology of Forgiveness', in C. R. Snyder and S. J. Lopez (eds.), Handbook of Positive Psychology (Oxford University Press, London), pp. 446-458.

McCullough, M. E. and E. L. Worthington: 1994, 'Models of Interpersonal Forgiveness and their Applications to Counseling: Review and Critique', Counseling and Values 39, 2-14.

McCullough, M. E., E. L. Worthington and K. C. Rachal: 1997, 'Interpersonal Forgiving in Close Relationships', Journal of Personality and Social Psychology 73, 321-336.

McKinley, W., C. M. Sanchez and A. G. Schick: 1995, 'Organizational Downsizing: Constraining, Cloning, and Learning', Academy of Management Executive 9, 32-44.

McNeely, B. L. and B. M. Meglino: 1994, 'The Role of Dispositional and Situational Antecedents in Prosocial Organizational Behavior: An Examination of the Intended Beneficiaries of Prosocial Behavior', Journal of Applied Psychology 79(6), 836-844.

Means, J. R., G. L. Wilson, C. Sturm, J. E. Biron and P. J. Bach: 1990, 'Theory and Practice: Humility as a Psychotherapeutic Formulation', Counseling Psychology Quarterly 3, $211-$ 215.

Morse, J.: 1999, 'The Missing Link between Virtue Theory and Business Ethics', Journal of Applied Philosophy 16(1), 47.

Nesteruk, J.: 1996, 'Law, Virtue, and the Corporation', American Business Law Journal 33(3), 473.

Park, N. and C. M. Peterson: 2003, 'Virtues and Organizations', in K. S. Cameron, J. E. Dutton and R. E. Quinn (eds.), Positive Organizational Scholarship: Foundations of a New Discipline (Berrett Koehler, San Francisco), pp. 33-47.

Peterson C. M. E. P. Seligman.: 2004, Character Strengths and Virtues: A Handbook and Classification (Oxford University Press, New York)..

Peterson, C.: 1991, Health and Optimism (Free Press, New York).

Pratt, M. G. and B. E. Ashforth: 2003, 'Fostering Meaningfulness in Working and at Work', in K. S. Cameron, J. E. Dutton and R. E. Quinn (eds.), Positive Organizational Scholarship: Foundations of a New Discipline (Berrett Koehler, San Francisco), pp. 309-327.

Rawls, J.: 1971, A Theory of Justice (Belknap Press of Harvard University Press, Cambridge, MA).

Richards, N.: 1992, Humility (Templeton University Press, Philadelphia).

Rogers, C. R.: 1951, On Becoming a Person (Houghton-Miflin, Boston).

Ryff, C. D. and E. Singer: 1998, 'The Contours of Human Health', Psychological Inquiry 8, 128. 
Schein, E. H.: 1992, Organizational Culture and Leadership 2 (Jossey-Bass, San Francisco).

Schudt, K.: 2000, 'Taming the Corporate Monster: An Aristotelian Approach to Corporate Virtues', Business Ethics Quarterly 10, 711-723.

Seligman, M. E. P.: 1991, Learned Optimism (Knopf, New York).

Seligman, M. E. P.: 2002a, Authentic Happiness (Free Press, New York).

Seligman, M. E. P.: 2002b, 'Positive Psychology, Positive Prevention, and Positive Therapy', in C. R. Snyder and S. Lopez (eds.), Handbook of Positive Psychology (Oxford University Press, New York), pp. 3-9.

Seligman, M. E. P. and M. Csikszentmihalyi: 2000, 'Positive Psychology: An Introduction', American Psychologist 55(1), 5-14.

Sethi, R. and C. Y. Nicholson: 2001, 'Structural and Contextual Correlates of Charged Behavior in Product Development Teams', Journal of Product Innovation Management 18, 154 168.

Singer, J. D.: 1998, 'Using SAS PROC MIXED to Fit Multilevel Models, Hierarchical Models, and Individual Growth Models', Journal of Education and Behavioral Studies 24(4), 323355 .

Snyder, C. R.: 2000, 'The Past and Possible Futures of Hope', Journal of Social and Clinical Psychology 2000 19(1), 11-28.

Snyder, C. R., D. B. Feldman, J. D. Taylor, L. L. Schroeder and V. H. Adams: 2000, 'The Roles of Hopeful Thinking in Preventing Problems and Enhancing Strengths', Applied and Preventive Psychology 9(4), 249-269.

Snyder, C. R., K. L. Rand and D. R. Sigmon: 2002, 'Hope Theory: A Member of the Positive Psychology Family', in C. R. Snyder and S. J. Lopez (eds.), Handbook of Positive Psychology (Oxford University Press, New York), pp. 257-276.

Solomon, R. C.: 1998, 'The Moral Psychology of Business: Care and Compassion in the Corporation', Business Ethics Quarterly 8, 515-533.

Spreitzer, G. M. and S. Sonenshein: 2003, 'Positive Deviance and Extraordinary Organizing', in S. Cameron, J. E. Dutton and R. E. Quinn (eds.), Positive Organizational Scholarship: Foundations of a New Discipline (Berrett Koehler, San Francisco), pp. 207-224.

Staw, B. M., L. E. Sandelands and J. E. Dutton: 1981, 'Threat-Rigidity Effects in Organizational Behavior: A Multilevel Analysis', Administrative Science Quarterly 26, 501-524.

Sternberg, J. J.: 1998, ‘A Balanced Theory of Wisdom', Review of General Psychology, 2, 347365.

Sutcliffe, K. M. and T. J. Vogus: 2003, ‘Organizing for Resilience', in K. S. Cameron, J. E. Dutton and R. E. Quinn (eds.), Positive Organizational Scholarship: Foundations of a New Discipline (Berrett Koehler, San Francisco), pp. 94-110. 
Tangney, J.: 2002, 'Humility', in C. R. Snyder and S. J. Lopez (eds.), Handbook of Positive Psychology (Oxford University Press, New York), pp. 411-419.

Tjeltveit, A. C.: 2003, 'Implicit Virtues, Divergent Goods, Multiple Communities', American Behavioral Scientist 47(4), 395-414.

Walsh, J. P.: 1999, 'Business Must Talk about its Social Role', in T. Dickson (eds.), Mastering Strategy: The Complete MBA Companion in Strategy (Pearson Education Limited, London), pp. 289-294.

Weick, K. E., K. M. Sutcliffe and D. Obstfeld: 1999, 'Organizing for Reliability: Processes of Collective Mindfulness', Research in Organizational Behavior 21, 81-123.

Weiser, J. and S. Zadek: 2000, Conversations with Disbelievers: Persuading Companies to Address Social Challenges (The Ford Foundation, New York)..

Witvliet, C. V., T. E. Ludwig and K. L. Vander Laan: 2001, 'Granting Forgiveness or Harboring Grudges: Implications for Emotion, Physiology, and Health', Psychological Science, 12(2), 117-123.

Wrzesniewski, A., C. McCauley, P. Rozin and B. Schwartz: 1997, 'Jobs, Careers, and Callings: People's Relations to their Work', Journal of Research in Personality 31, 21-33.

Wrzesniewski, A.: 2003, 'Finding Positive Meaning in Work', in K. S. Cameron, J. E. Dutton and R. E. Quinn (eds.), Positive Organizational Scholarship: Foundations of a New Discipline (Berrett Koehler, San Francisco), pp. 296-308.

Yamhure Thompson, L. and P. E. Shahen: 2003, 'Forgiveness in the Workplace', in R. C. Giacalone and C. L. Jurkiewicz (eds.), Handbook of Spirituality and Organizational Performance (M.E. Sharpe, New York), pp. 405-420.

\section{Appendix A}

Item Information for Virtuousness, Forgiveness, Responsibility, and Downsizing Pattern Matrix and Factor Loadings for Virtuousness and Forgiveness

\begin{tabular}{|l|l|c|c|}
\hline \multicolumn{1}{|c|}{ Item Name } & \multicolumn{1}{|c|}{ Description } & Virtue & Forgive \\
\hline KINDNESS1 & $\begin{array}{l}\text { This organization is characterized by many acts of concern and caring for } \\
\text { other people }\end{array}$ & 0.81 & \\
\hline KINDNESS2 $* *$ & Acts of compassion are common here & 0.87 & -0.12 \\
\hline KINDNESS3 & We are known as a caring and compassionate organization & 0.80 & \\
\hline KINDNESS4 & Kindness and benevolence are expected of everyone in the organization & 0.77 & -0.14 \\
\hline KINDNESS5 & $\begin{array}{l}\text { Many stories of compassion and concern circulate among organization } \\
\text { members }\end{array}$ & 0.81 & \\
\hline KINDNESS6 & $\begin{array}{l}\text { People are treated with courtesy, consideration, and respect in this } \\
\text { organization }\end{array}$ & 0.65 & 0.12 \\
\hline KINDNESS7 & $\begin{array}{l}\text { People are hired and promoted at least partly based on the interpersonal } \\
\text { support they provide to others }\end{array}$ & 0.58 & 0.12 \\
\hline KINDNESS8 & People here are cynical vs. people here are generally honoring & 0.58 & 0.17 \\
\hline HOPE1 & An optimistic and hopeful climate exists in this organization & 0.68 & 0.11 \\
\hline HOPE2 & We communicate and celebrate the successes of the organization & 0.74 & \\
\hline HOPE3** & A positive, enthusiastic environment is typical of this organization & 0.80 & \\
\hline
\end{tabular}




\begin{tabular}{|c|c|c|c|}
\hline HOPE4 & $\begin{array}{l}\text { We are optimistic that we will succeed, even when faced with major } \\
\text { challenges }\end{array}$ & 0.72 & \\
\hline HOPE5 & People have a sense that they can fulfill their potential in this organization & 0.63 & 0.18 \\
\hline HOPE6 & Everyone is energized by our belief in this organizations future success & 0.64 & 0.21 \\
\hline HUMILITY1** & People here demonstrate humility, or openness to improvement & 0.65 & \\
\hline HUMILITY2 & Arrogance and haughtiness are not typical of people in this organization & 0.53 & 0.16 \\
\hline HUMILITY3 & $\begin{array}{l}\text { Leaders in this organization are characterized more by humility than by self- } \\
\text { aggrandizement and self-promotion }\end{array}$ & 0.58 & 0.22 \\
\hline INTEGRITY1 & This organization demonstrates the highest levels of integrity & 0.76 & \\
\hline INTEGRITY2** & Honesty and trustworthiness are hallmarks of this organization & 0.79 & \\
\hline INTEGRITY3 & The culture of this organization advocates absolute honesty and truth telling & 0.79 & \\
\hline INTEGRITY4 & Our standards of integrity go well beyond the norm or the legal requirement & 0.84 & \\
\hline INTEGRITY5 & Employees trust one another in this organization & 0.58 & 0.17 \\
\hline INTEGRITY6 & Top management tells the truth & 0.48 & 0.34 \\
\hline INTEGRITY7 & People trust the leadership of this organization & 0.52 & 0.38 \\
\hline INTEGRITY8 & $\begin{array}{l}\text { Our organization acts unethically vs. our organization acts with high } \\
\text { integrity }\end{array}$ & 0.63 & 0.12 \\
\hline PURPOSE1 & This organization would be described as virtuous and honorable & 1.01 & \\
\hline PURPOSE2 & In this organization we are dedicated to doing good in addition to doing well & 0.84 & -0.11 \\
\hline PURPOSE $3 * *$ & This organization possesses a virtuous culture & 0.91 & \\
\hline PURPOSE4 & This organization provides mentors and models of virtuous behavior & 0.81 & \\
\hline PURPOSE5 & $\begin{array}{l}\text { Human beings and their development take precedence over financial assets } \\
\text { in management priorities }\end{array}$ & 0.71 & \\
\hline PURPOSE6 & $\begin{array}{l}\text { This organization rewards acts of compassion, generosity, courage, and } \\
\text { integrity }\end{array}$ & 0.71 & 0.10 \\
\hline PURPOSE7 & $\begin{array}{l}\text { In conversations among our leaders, words such as humility, forgiveness, } \\
\text { and compassion are common }\end{array}$ & 0.63 & \\
\hline PURPOSE8 & People love this organization & 0.58 & 0.23 \\
\hline PURPOSE9 & $\begin{array}{l}\text { Our organization is generally harmful vs. our organization is generally } \\
\text { virtuous }\end{array}$ & 0.60 & 0.14 \\
\hline PURPOSE10 & $\begin{array}{l}\text { In this organization we have a feeling that we are accomplishing something } \\
\text { greater than ourselves }\end{array}$ & 0.82 & -0.12 \\
\hline PURPOSE11 & A sense of profound purpose is associated with what we do here & 0.81 & -0.13 \\
\hline PURPOSE12 & $\begin{array}{l}\text { Many people define their position as a "calling" rather than just a job in this } \\
\text { organization }\end{array}$ & 0.60 & 0.13 \\
\hline PURPOSE13 & $\begin{array}{l}\text { This organization has extraordinary strengths but also a strong desire to } \\
\text { improve }\end{array}$ & 0.75 & -0.11 \\
\hline FORGIVE1 & $\begin{array}{l}\text { We feel little need to talk about the past downsizing and job eliminations } \\
\text { since they are now behind us }\end{array}$ & -0.10 & 0.47 \\
\hline FORGIVE2** & $\begin{array}{l}\text { Despite downsizing or job eliminations in the past, current employees have } \\
\text { no lingering grudges or ill feelings toward this organization. }\end{array}$ & & 0.90 \\
\hline FORGIVE3** & Any trust that was damaged as a result of downsizing has been restored & & 0.96 \\
\hline FORGIVE4** & $\begin{array}{l}\text { Personal relationships that were wounded have been re-established after the } \\
\text { downsizing }\end{array}$ & & 0.73 \\
\hline FORGIVE5 & $\begin{array}{l}\text { The high levels of trust and commitment to the organization will never be } \\
\text { regained (RECODED) }\end{array}$ & & 0.62 \\
\hline FORGIVE6** & Cynicism lingers as a result of the downsizing (RECODED) & & 0.72 \\
\hline
\end{tabular}

Principal Component Analysis, Promax with Kaiser Normalization.

Values less than 0.10 were suppressed.

**Items were retained in the final model.

Item Information for Responsibility: "When downsizing occurred, senior management expressed regret and apology for the personal difficulties created." 
See Cameron et al. (1987) and Cameron (1995) for validation of the Dirty Dozen Downsizing items, which included the following: (1) Employee loyalty to the organization has decreased. (2) Teamwork has deteriorated and people are more isolated. (3) Decision making has been pushed farther up in the organization. (4) Many of the best people have left. (5) Morale has decreased among organization members. (6) Organizational politics and coalition formation inside the organization have increased. (7) Conflict has increased among organization members. (8) Employees and top management have developed a short-term orientation. (9) Experimentation and creativity have declined among employees. (10) Criticism, complaints, and scapegoating directed at top management have increased. (11) People are more resistant to change. (12) People have become less willing to communicate openly and share information. All items were based on a $1-6$ scale of response. 